\title{
Micro electro discharge drilling in carbon fiber reinforced composites
}

\author{
Pramod Kumar Agrawal *, Ravinder Kumar and Inderdeep Singh \\ Department of Mechanical and Industrial Engineering, \\ Indian Institute of Technology Roorkee, Uttarakhand, 247667 \\ *Email: bittu.bit2013@gmail.com
}

The application of Carbon fiber reinforced plastic (CFRP) are growing in the aerospace industries, including rocket exit nozzles, nose caps, pistons for internal combustion engines, and fusion devices because of their light-weight and excellent mechanical properties [1]. This paper presents the micro electric discharge through-hole drilling in carbon fiber reinforced polymer matrix composites. The micro electric discharge drilling was carried out at 'Hyper 15' electric discharge machine by Synergy Nano Systems. The CFRP composite was fabricated by hand layup process. A micro tool of diameter $110 \mu \mathrm{m}$ was made from a $1 \mathrm{~mm}$ diameter tungsten rod using wire electric discharge grinding (WEDG). The CFRP workpiece was prepared by abrading the ends normal to the fiber strands with the help of sand paper (grit size 800). Through holes of diameter $110 \mu \mathrm{m}$ and depth $1.2 \mathrm{~mm}$ were drilled in the fiber strands of width $150 \mu \mathrm{m}$. The fiber strands of such a small width are not visible with the naked eye, therefore, a charge couple device (CCD) camera was used to detect the fiber strand and the tool was positioned exactly on it. The wrong positioning (i.e. overlapping of the tool on the epoxy) results in the tool breakage. A machining depth of 1.4 $\mathrm{mm}$ was programmed for the workpiece thickness of $1.2 \mathrm{~mm}$. This extra travel of $200 \mu \mathrm{m}$ of the tool was given to prevent the effect of tool longitudinal wear and corner wear on the hole exit. The tool entry and tool exit of a hole is shown in figure 1 .

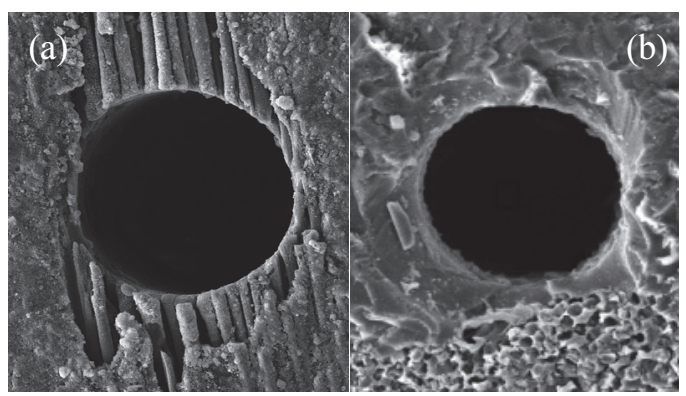

Figure 1: Micro hole (a) Tool entry (b) Tool exit

Taguchi L9 orthogonal design was used for the design of experiments taking four factors at three levels each. Nine experiments were conducted using Taguchi L9 orthogonal design taking input parameters as voltage, capacitance, feed and tool rotational speed. Material removal rate (MRR) was calculated by calculating the volume of the eroded cylinder divided by the machining time. Analysis of variance (ANOVA) was studied and effects of input parameters on output response were explored. Figure 2 shows the effect of input parameters on the material removal rate (MRR). The increased value of voltage or capacitance produces more heat energy in the workpiece. This heat energy enhances the phenomenon of melting and evaporation resulting in higher MRR [2]. Higher amount of feed to the tool electrode results in lower machining time and hence higher MRR. The tool rotational speed shows a decreasing as well as increasing trend with the MRR. It decreases at 1250 RPM first and then again increases at 1500 RPM.

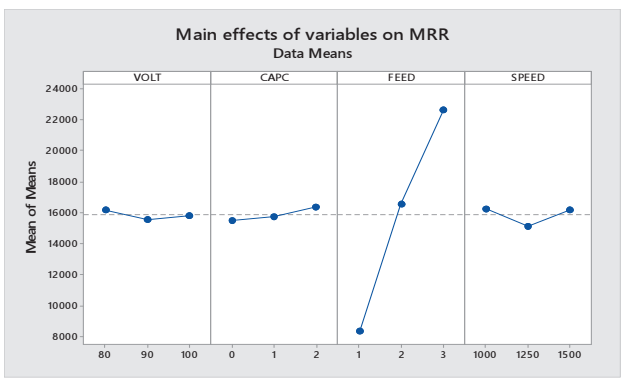

Figure 2: Effects of input variables on MRR

The micro holes were examined using scanning electron microscope and it was found that it is feasible to produce micro through-holes in the CFRP by EDM without any surface damage like delamination and fiber pullout which is produced during conventional drilling.

The present study shows the possibility of making micro through-holes in the CFRP with an aspect ratio of 11 or higher. This possibility opens up another field of application for the CFRPs.

\section{References}

1. Y. H. Guu, H. Hocheng, N. H. Tai, S. Y. Liu J. Mater. Sci. 36 (2001) 2037-2043.

2.U. Teicher, S. Müller, J. Münzner, A. Nestler, Procedia CIRP 6 (2013) 320-325. 